\section{Revista}

Ibero-Americana

de Estratégıa

\title{
DINÂMICA DE STAKEHOLDERS E COCRIAÇÃO DE VALOR EM MUSEUS: UM OLHAR INICIAL
}

DYNAMICS OF STAKEHOLDERS AND CO-CREATION OF VALUE IN MUSEUMS: AN INITIAL LOOK

DINÁMICA DE STAKEHOLDERS Y LA CO-CREACIÓN DE VALOR EN LOS MUSEOS: UNA PERCEPCIÓN INICIAL

\author{
Andréa do Prado Zago \\ Mestre em Hospitalidade pela Universidade Anhembi Morumbi - UAM \\ Professora da União das Instituições Educacionais do Estado de São Paulo \\ E-mail: apradozago@gmail.com (Brasil)
}

\section{Elizabeth Kyoko Wada}

Doutora em Ciências da Comunicação pela Universidade de São Paulo - USP

Professora e coordenadora do Programa de Mestrado em Hospitalidade da Universidade Anhembi Morumbi - UAM

E-mail: ewada@uol.com.br (Brasil) 
Dinâmica de Stakeholders e Cocriação de Valor em Museus: Um Olhar Inicial

\title{
DINÂMICA DE STAKEHOLDERS E COCRIAÇÃO DE VALOR EM MUSEUS: UM OLHAR INICIAL
}

\section{RESUMO}

A pesquisa da dinâmica de stakeholders em museus está relacionada à busca de compreensão de quem são os envolvidos pela gestão na formação e desenvolvimento dos espaços considerando os aspectos da cocriação de valor. O estudo justifica-se pela importância dessas instituições enquanto vetores de conservação, comunicação e difusão de elementos tangíveis e intangíveis de uma localidade e pelo crescimento do número de museus em diversas cidades, especialmente em Belo Horizonte, MG. O objetivo geral foi compreender e analisar a gestão do relacionamento de dois museus do Circuito Cultural Praça da Liberdade (Espaço TIM UFMG do Conhecimento e Memorial Minas Gerais) com seus stakeholders. Foi desenvolvida uma pesquisa com abordagem qualitativa e com metodologia voltada para estudo de casos múltiplos. Foram utilizados para coleta de dados três fontes de evidência: entrevistas semiestruturadas, observação direta e análise documental. Foi possível identificar na pesquisa que a gestão atual dos museus não estabelece monitoramento constante de stakeholders primários como a comunidade local. Destaca-se que a gestão considerando quesitos básicos da cocriação de valor como transparência e engajamento de stakeholders pode resultar no desenvolvimento estratégico e colaborativo de benefícios recíprocos e no envolvimento espontâneo da comunidade local.

Palavras chave: Stakeholders; Cocriação; Museus.

\section{DYNAMICS OF STAKEHOLDERS AND CO-CREATION OF VALUE IN MUSEUMS: AN INITIAL LOOK}

\begin{abstract}
The study of the dynamics of stakeholders in museums is about the understanding of which groups are evolved by the management of these spaces, considering the aspects of co-creation of value. The study is justified by the importance of these institutions as vectors for conservation, communication and dissemination of tangible and intangible elements of a locality and the growing number of museums in various localities, especially in Belo Horizonte, MG. The main objective was to understand and analyze the management of the relationship of two museums in the Circuito Cultural Praça da Liberdade (Espaço TIM UFMG do Conhecimento and Memorial Minas Gerais) with its stakeholders. It was developed a qualitative research, focused on multiple case studies with three sources of evidence: interviews, direct observations and documentation. It was identified in this research that the currents museums management does not estabilish constant monitoring of primary stakeholders as the local community. It is found that the basic requirements management considering to the cocreation of value such as transparency and stakeholder engagement can result in the strategic development, collaborative reciprocal benefits and spontaneous involvement of the local community.
\end{abstract}

Keywords: Stakeholders; Co-Creation; Museums.

Revista Ibero-Americana de Estratégia - RIAE, São Paulo, v. 12, n. 2, p. 274-298, abr./jun. 2013. 


\section{LA DINÁMICA DE LOS STAKEHOLDERS Y LA CO-CREACIÓN DE VALOR EN MUSEOS: UNA MIRADA INICIAL}

\section{RESUMEN}

La investigación de la dinámica de los stakeholders en museos está relacionada a la búsqueda de la comprensión de quienes son los involucrados por la gestión en la formación y desarrollo de los espacios, considerando los aspectos de la co-creación de valor. El estudio se justifica por la importancia de esas instituciones como vectores de conservación, comunicación y difusión de elementos tangibles e intangibles de una localidad y por el crecimiento del número de museos en diversas ciudades, especialmente en Belo Horizonte, MG. El objetivo general fue comprender y analizar la gestión del relacionamiento de dos museos del Circuito Cultural Praça da Liberdade (Espacio TIM UFMG del Conocimiento y Memorial Minas Gerais) con sus stakeholders. Fue desarrollada una investigación con enfoque cualitativo y con metodología de estudio de casos múltiplos. Se utilizaron para la recolecta de los datos tres fuentes de evidencias: entrevistas semiestructuradas, observación directa y análisis documental. Fue posible identificar en la investigación que la gestión actual de los museos no establece monitoreo constante de los stakeholders primarios como la comunidad local. Se destaca que la gestión, considerando los requisitos básicos de la co-creación de valor como transparencia y compromiso de los stakeholders, puede resultar en el desarrollo estratégico y colaborativo de beneficios recíprocos y en la participación espontanea de la comunidad local.

Palabras clave: Stakeholders; Co-Creación; Museos. 
Dinâmica de Stakeholders e Cocriação de Valor em Museus: Um Olhar Inicial

\section{INTRODUÇÃO}

A busca por teorias que orientem a administração de empresas e organizações é antiga. A partir da década de 1970, ocorreram algumas mudanças que alteraram drasticamente a forma de produção e as estruturas sociais das empresas e organizações, o que acarretou na necessidade de um posicionamento estratégico ainda maior. A globalização e o advento das novas tecnologias da informação e de comunicação são citadas por Castells (1999) como as grandes transformadoras do mundo contemporâneo e formadoras da configuração do que o autor chama de "a sociedade em rede". Essas mudanças passaram a influenciar diretamente as empresas, o governo e a sociedade em geral, incluindo os processos de comunicação e socialização, cujos impactos ainda são recentes e começam a ser estudados. Devido às facilidades tecnológicas, as distâncias tornaram-se menores e a concorrência passou de local/regional para global (Castells, 1999).

Como reflexo dessas mudanças surgiu uma teoria que busca perceber as diversas influências do mundo contemporâneo e posicionar as empresas a partir da análise das suas diversas relações: a teoria dos stakeholders. Stakeholders (sem tradução para o português) é uma palavra em inglês definida por Freeman (1984) como diversos grupos ou indivíduos que influenciam ou podem ser influenciados por uma organização. Apesar de ser uma palavra relativamente nova, já existe um leque de definições e entendimentos desde uma abordagem mais simplista até a mais ampla. Friedman e Miles (2006) pesquisaram 75 textos sobre a teoria e encontraram, aproximadamente, 55 definições do termo. Essa pesquisa é orientada pela definição de Freeman (1984) que tem abordagem ampla, uma vez que avalia não apenas os grupos que influenciam as organizações como aqueles que são influenciados por ela.

Mitchell, Agle e Wood (1997) afirmam que a abordagem dos stakeholders tem sido fundamental para a compreensão da empresa sobre seu papel e responsabilidade para com os demais envolvidos direta ou indiretamente no negócio. Isso porque a teoria dos stakeholders tem como unidade de análise o relacionamento da empresa com os diversos grupos ou indivíduos que afetam e são afetados por essa. Fundamenta-se na afirmação de que pra ter sucesso a empresa deve reconhecer e administrar o relacionamento com seus diversos stakeholders. Assim, entender a dinâmica de stakeholders é compreender a complexidade de interesses envolvidos relacionados à determinada empresa, podendo servir de base para o desenvolvimento de uma série de atividades na empresa e compreensão de como os relacionamentos são administrados de forma a cocoricar valor nas empresas.

A cocriação de valor é o envolvimento dos diversos stakeholders para desenvolver conjuntamente experiência de valor. O processo de cocriação “[...] explora as percepções, os 
conhecimentos, as habilidades e a criatividade de todos os participantes de forma mutualmente valiosa (RAMASWAMY e GOUILLART, 2010, p.247)”. Assim, os benefícios são tanto para empresa que melhora a oferta e desenvolve uma comunicação direta com os stakeholders quanto para esses últimos que recebem melhores produtos e serviços, tendo assim melhores experiências de consumo, desenvolvendo então a economicidade da rede.

O processo de cocriação de valor tem quatro elementos básicos fundamentais: diálogo, acesso, avaliação do risco e transparência. Os quatro elementos condicionam e formam a base da cocriação de valor: 1) modelo mental de experiências; 2) interações contextuais; 3) plataformas de engajamento; 4) economicidade das redes (RAMASWAMY e GOUILLART, 2010).

A cocriação de valor direciona as empresas na mudança do foco oferta de serviço ou produto para a experiência do consumidor. É mais que personalizar, é compreender o universo dos stakeholders e inseri-los no processo de criação/melhoramento da oferta de forma a beneficiar todos envolvidos, ou seja, uma abordagem participativa.

Considerando as diversas funções sociais dos museus, os diversos stakeholders a serem trabalhados pela gestão e o grande aumento recente no número dessas instituições ${ }^{1}$, mostra-se pertinente o entendimento da teoria dos stakeholders e os aspectos da cocriação de valor nesses espaços. Utilizar teorias da administração pode auxiliar a um entendimento complexo e profissional de um trabalho com questões intangíveis, como a área cultural.

Dentre as funções sociais dos museus estão: conservar, comunicar, difundir elementos tangíveis e intangíveis com propósito de educação, estudo e lazer (ICOM, 2007). Para um país, os museus são de "fundamental importância para valorização do patrimônio cultural como dispositivo estratégico de aprimoramento dos processos democráticos" (MinC, 2007). Economicamente, esses espaços têm importância singular e grande potencial para o desenvolvimento da economia criativa (desenvolvimento local), promoção e composição do turismo de diversas localidades. O museu do Louvre e o Centro Cultural Pompidou em Paris (França), o Museu Guggenheim em Bilbao (Espanha), Inhapim em Brumadinho, Minas Gerais (Brasil) e o Memorial do Homem Cariri em Nova Olinda, Ceará (Brasil) são alguns exemplos notórios de museus que geraram desenvolvimento econômico, social e cultural. Entretanto, esses espaços têm grandes desafios econômicos para se manter e necessitam em grande parte de apoiadores, patrocinadores e doadores, sendo o governo um stakeholder de extrema importância por determinar as possibilidades de financiamento (leis

\footnotetext{
${ }^{1}$ De acordo com dados do Guia de Museus do IBRAM (2011), Belo Horizonte tem 38 museus e centros culturais cadastrados, sendo um desses itinerante, 1 atualmente fechado e 3 pertencentes ao CCPL (o Museu Mineiro está temporariamente em reforma). Assim que todos os espaços do circuito forem inaugurados, o CCPL irá representar um quarto da oferta de museus e centros culturais da cidade.
}

Revista Ibero-Americana de Estratégia - RIAE, São Paulo, v. 12, n. 2, p. 274-298, abr./jun. 2013. 
culturais, principalmente leis de incentivo à cultura) e por ser um agente financiador (fundo de cultura). Buscou-se aprofundar nas teorias e realizar uma análise de como a gestão de espaços culturais trabalha a potencialidade do relacionamento com os stakeholders e utiliza a abordagem da cocriação para desenvolvimendo da economicidade das redes e benefícios recíprocos para todos stakeholders. Para tanto, definiu-se a pergunta orientadora: a administração de espaços culturais compreende a inserção e influência de stakeholders na gestão do espaço e utiliza aspectos da abordagem da cocriação de valor?

Propõe-se então como objetivo geral compreender e analisar a gestão do relacionamento entre dois museus do Circuito Cultural Praça da Liberdade (CCPL) com seus stakeholders destacando os aspectos da cocriação de valor. Os objetivos específicos são: identificar os stakeholders dos museus do CCPL; hierarquizar a importância de cada um dos stakeholders de acordo com a percepção dos gestores e identificar o relacionamento desenvolvido com esses; perceber se os elementos base da cocriação de valor são utilizados pelos museus envolvendo os diversos stakeholders.

Foram escolhidos dois museus do Circuito Cultural Praça da Liberdade, Belo Horizonte MG. Esse circuito foi viabilizado após a construção do centro administrativo na zona norte da capital mineira em janeiro de 2010 que tinha como objetivo unificar em um espaço todo poder administrativo do estado e guiar o crescimento urbano da cidade. Os prédios históricos que desde a construção da capital mineira eram destinados às secretarias e ao palácio do governador foram desocupados e tornaram-se (alguns ainda estão em reforma) museus e centros culturais. Até dezembro de 2011 foram inaugurados o Espaço TIM UFMG de Conhecimento, o museu das Minas e do Metal, o Memorial Minas Gerais - Vale e o Palácio da Liberdade sendo os investidores a empresa EBX, TIM e UFMG, Vale e o Instituto OI Futuro (fez a restauração, mas não continua na gestão). Ainda estão em restauração o Centro de Arte Popular (Cemig), Centro Cultural Banco do Brasil (Banco do Brasil), Museu Clube da Esquina, Museu do Homem Brasileiro e Museu do Automóvel2. Todos esses espaços somados à biblioteca Pública Estadual Luiz de Bessa, o Arquivo Público Mineiro e o Museu Mineiro foram o CCPL. Para um estudo direcionado foram escolhidos dois museus com característica semelhantes para viabilização de posterior comparação, o Espaço TIM UFMG do Conhecimento e o Memorial Minas Gerais - Vale.

Revista Ibero-Americana de Estratégia - RIAE, São Paulo, v. 12, n. 2, p. 274-298, abr./jun. 2013. 


\section{FUNDAMENTAÇÃO TEÓRICA}

A teoria dos stakeholders tem sido discutida há cerca de cinco décadas, mas ainda são poucos os relatos da aplicação da teoria na administração das empresas, especialmente em museus. Os autores têm focado em quatro abordagens da teoria: descritiva, instrumental, normativa e gerencial (DONALDSON e PRESTON, 1995, MITCHELL, AGLE, WOOD, 1997; FRIEDMAN e MILES, 2006, REED et al, 2009, FREEMAN et al, 2010).

Donaldson e Preston (1995) dizem que a teoria dos stakeholders é incontestavelmente descritiva, pois se apresenta descrevendo como a empresa é, quem são seus stakeholders, como ocorre o relacionamento traçando assim uma constelação de interesses cooperativos e competitivos.

Reed et al (2009) apontam que a abordagem descritiva é raramente utilizada separadamente e que a diferença significativa está entre a abordagem instrumental e a normativa. A abordagem normativa lista o porquê a empresa deve administrar o relacionamento com seus stakeholders contando com fundamentos filosóficos e morais e, neste caso, envolvendo também a sustentabilidade da empresa. Como o próprio nome diz, esta perspectiva se está de acordo com as "normas" socialmente aceitas. Reed et al (2009) citam duas grandes influências no aspecto normativo: a teoria da ação comunicativa de Hebermas (1984, 1987 apud REED et al 2009) e a metodologia de sistemas flexíveis de Checkland (1999 apud REED et al (2009)). Ambas reconhecem que os problemas devem ser tratados com um sistema flexível envolvendo diferentes stakeholders que cooperam, discutem e buscam um consenso. Nesse sentido é muito utilizada no desenvolvimento de políticas (legitimando as decisões que são feitas) e na literatura de gestão ambiental, quando o resultado buscado é o participativo, construção social real e verdadeira. No entanto, "stakeholder analysis in itself does not create this platform for negotiation, but can be used as a tool to contribute to this negotiation or learning between stakeholders" (REED et al, 2009, p.1935).

A abordagem instrumental estabelece quadros para examinar as conexões entre a prática da gestão de stakeholders e a realização de metas de desempenho da empresa, ou seja, identificam os stakeholders e formulam pesquisas pra gerenciar o comportamento, relacionando assim os meios aos fins. Demonstra que as empresas que adotam a gestão dos stakeholders obterão sucesso e que é necessário dar prioridade a alguns stakeholders específicos, hierarquizando-os de acordo com a necessidade (DONALDSON e PRESTON, 1995).

\footnotetext{
${ }^{2}$ A análise de stakeholders em si não cria plataforma de negociação, mas pode ser usada como ferramenta que contribui para essa negociação e aprendizado entre stakeholders (tradução da autora).
} 
A abordagem gerencial é a junção das demais somada à recomendação de atitudes, procedimentos e práticas sistemáticas (DONALDSON e PRESTON, 1995). Corroborando com a quarta abordagem, Freeman e McVea (2001), afirmam que a teoria é essencialmente gerencial e que não dá para separar o caráter normativo do descritivo e instrumental (empírico). A análise de stakeholders ocorre de forma sistemática por meio de um mapa racional, etapas e definição de prioridades na administração. Enquanto alguns relacionamentos requerem atenção constante, outros precisam apenas ser monitorados, observados (FROOMAN, 1999).

Reed et al (2009) indicam três passos para gerenciamento de stakeholders: o primeiro é identificar os stakeholders, o segundo é diferenciá-los e categorizá-los e por fim investigar os relacionamentos, sendo indicados métodos específicos para cada passo. Assim como para Reed et al (2009), o primeiro passo indicado por Freeman (1984) para administração de stakeholders é mapear e entender quais são os stakeholders da organização e fazer uma análise desses. Para construir o "mapa racional de stakeholders" deve-se primeiro considerar o histórico do ambiente da empresa.

Sabe-se que os stakeholders têm diferentes relacionamentos com as empresas e por isso após o mapeamento há a necessidade de hierarquização para direcionamento do monitoramento e de ações específicas da empresa. Clarkson (1995, p.106) divide os stakeholders em primários e secundários. Os primários são aqueles críticos que tem influência direta na empresa como: acionistas e investidores, os empregados, os consumidores, os fornecedores, clientes e, ainda, os public stakeholders, ou seja, os que interferem diretamente como o governo com taxas, legislação reguladora da atividade, etc. Este grupo define grande parte do negócio e certamente requerem uma atenção especial. Os secundários, embora não sejam críticos para a empresa na data da construção do mapa, podem tornar-se com o passar do tempo, como por exemplo, uma ONG que defende os direitos de pessoas com deficiência física e podem impor mudanças estruturais em um espaço cultural.

Após construir um mapa racional de stakeholders, é necessário desenvolver alguns pontos para que o gerenciamento de todos seja possível, ainda que orientados segundo relevância e necessidade de atendimento.

Freeman, Harisson e Wicks (2007) ordenam sete técnicas para administrar os stakeholders:

1) Avaliação dos stakeholders;

2) Análise do comportamento dos stakeholders;

3) Entender os stakeholders em profundidade;

1) Avaliação das estratégias dos stakeholders baseando na combinação entre as variáveis competitividade (alta e baixa) e cooperação (alta e baixa); 
2) Desenvolver estratégias específicas para os stakeholders utilizando de técnicas específicas como: criação de valor com mudança das regras, criação de valor com estratégias ofensivas, criação de valor com estratégias defensivas, criação de valor pela realização das estratégias já definidas;

3) Criação de novas formas de interação com stakeholders. Acessibilidade, engajamento, diálogo e negociação;

4) Desenvolvimento integrado de técnicas para stakeholders.

Ressalta-se que existem muitas metodologias de identificação, hierarquização e investigação e que, a escolha irá variar de acordo com a proposta da análise de stakeholders.

Freeman, Harisson e Wicks (2007) afirmam que a utilização das técnicas e princípios apresentados sobre a teoria dos stakeholders não é apenas uma possibilidade de gestão, mas uma forma ética e sustentável de trabalhar. Junqueira e Wada (2011) apontam que "o envolvimento das organizações com seus grupos de interesses requer conhecimento para que se tenha uma relação que seja construtiva e produtiva para os envolvidos no negócio". A gestão de stakeholders abre possibilidades de constantes monitoramentos sobre o ambiente interno e externo que variam de organização para organização. Sendo assim, a teoria atua como base para orientação holística da aplicação de conceitos na empresa como estratégia empresarial, cooperativismo, sustentabilidade e cocriação de valor.

Desta forma, a teoria dos stakeholders oferece a base sólida no processo de desenvolvimento da cocriação de valor. O princípio central da cocriação de valor é: “engajar pessoas para criar juntas experiências de valor e ao mesmo tempo, aperfeiçoar a economicidade das redes" (RAMASWAMY e GOUILLART, 2010, p.35). As experiências são criadas juntas não apenas empresa com cliente, mas envolve os diversos stakeholders. Nesse sentido, processo de criação de valor está inerentemente ligado a ética e valores e por isso, é necessário em primeiro lugar mapear e entender quem são os stakeholders para os quais e com os quais a empresa irá “criar” valor.

Os quatro elementos básicos da cocriação de valor são: diálogo, acesso, avaliação do risco e transparência. "Diálogo significa interatividade, envolvimento profundo e propensão a agir - por ambas as partes", ou seja, é direto e focado em assuntos que interessam ao consumidor e à empresa em um fórum propício ao diálogo com regras (explícitas ou implícitas). Refere-se a compartilhamento e comunicação em igualdade de condições. "O acesso começa com informação e ferramentas" e possibilita experiências desejáveis sem existir a necessidade de aquisição. O gerenciamento de riscos é referente à probabilidade de danos ao consumidor. É a transparência de 
diálogo e de fornecimento de informação sobre os possíveis riscos, assumindo que não apenas a empresa pode avaliar e gerenciar os riscos como também os clientes. Busca-se na atualidade além de apenas a informação de que foi "testado e aprovado". A transparência é uma consequência necessária para efetivação dos outros elementos e, a medida que as informações tornam-se cada vez mais acessíveis, a assimetria de informações entre empresa e demais stakeholders começa a desaparecer. A transparência aumenta a capacidade de escolha consciente dos clientes e de desenvolver confiança (PRAHALAD e RAMASWAMY, 2004).

Os quatro elementos base condicionam a estrutura da cocriação de valor:

(1) modelo mental de experiências;

(2) interações contextuais;

(3) plataformas de engajamento;

(4) economicidade das redes.

O modelo mental de experiências, representa as singularidades, ou seja, ainda que a empresa atenda 100 milhões de pessoas, o foco deve ser centrado na experiência e não em bens e serviços. As interações contextuais são a capacidade de envolvimento em diversos momentos com os diferentes stakeholders. As plataformas de engajamento são múltiplas e se apresentam de diversas formas, sendo desde plataformas de debate on-line a reuniões presenciais e centros de chamada telefônicas. Essas plataformas devem ser constantemente desenhadas de acordo com a evolução e inovações das empresas geradas pela cocriação resultando assim um design thinking. A função dessas plataformas é proporcionar interações que resultem em experiências humanas e, para uma mudança em larga escala torna-se necessário a intermediação tecnológica. "As novas experiências e a melhoria dos aspectos econômicos constituem os frutos desse processo, enquanto as plataformas de engajamento são como as árvores que produzem os frutos" (RAMASWAMY e GOUILLART, 2010, p.36). Por fim, a economicidade das redes é impulsionada pelo avanço das ferramentas de colaboração, redes de informação e comunicação. As interações co-criativas expandem o valor mútuo das redes. Quando as empresas co-criam com os fornecedores, por exemplo, soluções podem ser encontradas para que o resultado da experiência a ser proporcionada melhore e o relacionamento entre as partes aprimore (RAMASWAMY e GOUILLART, 2010).

Independente do tamanho da empresa e do setor é possível que esta se engaje no processo de cocriação. Govier (2008) afirma que se não houver o comprometimento desde o topo da organização com a cocriação de valor, essa simplesmente não irá acontecer. O processo de mudança requer envolvimento de diversos stakeholders: os funcionários são envolvidos desde o início, ou 
seja, cocriar desde o processo de mudança e não a utilização de um processo pré-definido. $\mathrm{O}$ processo de mudança concebido previamente por gestores corre o risco de manter o mesmo padrão do negócio e não envolver os stakeholders, estando assim a um passo do fracasso. Os clientes também são parte integrante no processo de transformação, tendo um papel importante da criatividade investida na busca de melhores experiências. Isso porque o centro da mudança é a experiência dos stakeholders, especialmente do cliente, e não os processos da empresa. Ou seja, os clientes não apenas recebem o produto como participam da elaboração. Os funcionários e fornecedores fazem além do operacional, focam no desenvolvimento da experiência e participam do processo de aprimoramento (RAMASWAMY e GOUILLART, 2010).

Há, nesse processo, o deslocamento do foco do produto e do serviço (antigo paradigma de criar valor pra o cliente) para o foco na experiência. Isso significa dizer que há de existir uma sintonia entre uma rede de stakeholders internos e externos em conjunto com uma forma de codificação da mensagem (sob o impulso da conectividade e da tecnologia), para que seja criado valores exclusivos para cada cliente. Isso porque a cocriação refere-se a customização de bens e serviços com e para os clientes(internos e externos) e até produtos direcionados à massa, para que se possa proporcionar experiências personalizadas (RAMASWAMY e GOUILLART, 2010).

A base para o desenvolvimento de cocriação de valor é o cooperativismo. Os diversos stakeholders colaboram para conseguir benefícios. Prahalad e Krishnan (2008) fornecem muitos exemplos ligados à tecnologia como software abertos que os internautas podem editá-lo. Os autores são enfáticos ao afirmar que o crescimento das empresas e o acesso a rede global dependerá de cocriar experiências singulares com e para os clientes (grifo nosso). Para tanto, afirmam que além da customização de atendimento ao clinete e do foco na experiência, será necessário a promover uma rede de colaboração não apenas interna, como para além da empresa.

Dentre os benefícios da cocriação de valor pode-se citar novas interações e melhora na satisfação do cliente, funcionários, fornecedores e demais stakeholders; melhora na qualidade dos produtos e serviços; desenvolvimento de novos produtos e inovação; crescimento sustentável; reforço na legitimidade social dos empreendimentos. Quatro vantagens são destacadas por Ramaswamy e Gouillart (2010): maior capital estratégico e retornos para empresa, novas experiências de valor para os indivíduos, menor risco e custos para as organizações, menor risco e custos para os indivíduos.

O processo de cocriação de valor para stakeholders aborda também questões éticas, democráticas e existe por uma razão pragmática: o valor é o que faz qualquer empresa ter sucesso, ou seja, uma forma assertiva de oferecer bons produtos e serviços (FREEMAN, HARISSON E 
WICKS, 2007). Para o profissional que utiliza a cocriação de valor na gestão, Govier (2008) afirma que além de ser democrático, terá diversos benefícios, dentre eles um um ótimo projeto (o autor analiza projetos de exposição em museus), não apenas para empresa, mas para todos envolvidos.

[...] co-creation is about far more than democracy. But anyway, we do need to lead: partly because we have responsibilities (for our collections, for our commercial viability, for our participants and for our own professional reputations), and partly because we want cocreated projects to be the best that they can be, for everyone involved (GOVIER, 2008,p. $35) .^{3}$

Todos os ramos de bens e serviços podem utilizar a cocriação de valor como estratégia empresarial. Mensh e Mensh (2010) afirmam que os museus eram formados por grandes coleções até então sistematizadas de forma estática. O colecionismo não mudou, mas há atualmente novos processos e procedimentos para que sejam apresentados de forma dinâmica, salientando a experiência particular de cada pessoa.

In the beginning of the twenty-first century, the term Museum 2.0 became the symbol of a new museum model, involving new concepts about museum work as a profession and the new canonization of processes and procedures. The keywords of this transformation are participation and co-creation (MENSH E MENSH, 2010, p.33).4

Para poder compreender a dinâmica de stakeholders e as possibilidades de desenvolvimento do processo de cocriação de valor em museus e espaços culturais, faz-se necessário um estudo de casos múltiplos considerando os aspectos principais dessas organizações, os stakeholders relevantes, participação e formas de gestão.

\section{METODOLOGIA}

Para poder atingir os objetivos do estudo e relacionar a teoria dos stakeholders e a abordagem da cocriação de valor à gestão dos centros culturais do CCPL, foi desenvolvido uma pesquisa estruturada com abordagem qualitativa com metodologia voltada para estudo de casos múltiplos. A pesquisa estruturada descrever e ressaltar evidências de cada caso estudado para

\footnotetext{
${ }^{3}$ Cocriação é muito mais do que democracia. Mas de qualquer forma, precisamos desenvolver pois: em parte porque temos responsabilidades (com nossas coleções, com nossa viabilidade comercial, com nossos participantes e para nossa própria reputação profissional) e, em parte porque nós queremos que os projetos cocriados sejam o melhor possível para todos envolvidos (tradução da autora).

${ }^{4}$ No começo do século vinte, o termo museu 2.0 tornou-se símbolo de um novo modelo de museu, envolvendo novos conceitos do trabalho no museu, assim como da profissão, novos processos e procedimentos. As palavras chaves dessa transformação são participação e cocriação.
} 
possível análise comparativa. A abordagem de estudo de caso ou estudo de casos múltiplos é uma estratégia de pesquisa centrada no entendimento de processos empíricos da dinâmica atual presentes em configurações individuais. De acordo com Eisenhardt (1989) estudos de caso podem ser utilizados com vários propósitos: descrever, testar uma teoria ou ser base para o desenvolvimento de uma teoria. O propósito do estudo de caso em questão é descrever a atual gestão de dois espaços culturais para possível comparação e análise inicial da inserção de diferentes stakeholders na gestão e nas ações de cocriação de valor. A escolha da metodologia justifica-se especialmente por se tratar de um estudo descritivo que busca evidências e possíveis relações na gestão de dois espaços recentes que possuem grandes investidores e parcerias com espaços culturais tradicionais. Optou-se por utilizar o estudo de casos múltiplos para possível comparação dos diferentes espaços culturais pesquisados. O procedimento metodológico de estudo de casos múltiplos é um diferencial na identificação e entendimento das diversas relações diretamente ligadas ao desenvolvimento de ações estratégicas, éticas, sustentáveis, de cooperação e cocriação de valor. Foram selecionados os dois museus do CCPL que estão já estão em funcionamento: Espaço TIM UFMG do Conhecimento e o Memorial Minas Gerais - Vale. e Museu das Minas e do Metal. Os três espaços culturais foram inaugurados em 2010, funcionam de terça feira à domingo e atuam por meio da parceria públicoprivada. Foi realizado contato por e-mail, telefone e pessoalmente no museu das Minas e do Metal para o agendamento da entrevista com a diretora. A diretora não teve disponibilidade para ser entrevistada e não achou conveniente encaminhar para outra pessoa. O roteiro da entrevista foi enviado por e-mail, mas não houve retorno e por esse motivo, não foi possível realizar o estudo de caso do terceiro espaço cultural. O outro espaço cultural inaugurado, o Palácio da Liberdade, não foi pesquisado, pois não é considerado museu, apenas sede histórica. O Palácio da Liberdade é administrado pela Superintendência de Administração de Palácios e ainda atende à demandas do governador de Minas Gerais durante a semana, sendo aberto apenas domingo de 9 às 13 horas para visitação.

A primeira etapa do estudo foi a revisão da literatura a partir de: a) fundamentos teóricos sobre a teoria dos stakeholders $e$ cocriação de valor; b) história e aspectos administrativos de museus. O objetivo desta etapa é aprofundar a base teórica para poder correlacionar com o estudo empírico. Também na primeira etapa foram feitos os primeiros levantamentos e estudos referentes às organizações a serem pesquisadas. Foram pesquisados os sites do CCPL, da Belotur, das Secretarias de Turismo e de Cultura de Minas Gerais, e dos Ministérios do Turismo e da Cultura; revistas e jornais sobre esse circuito e o primeiro projeto elaborado pelo ex-governador e então senador Francelino Pereira em 1997.

Revista Ibero-Americana de Estratégia - RIAE, São Paulo, v. 12, n. 2, p. 274-298, abr./jun. 2013. 
Dinâmica de Stakeholders e Cocriação de Valor em Museus: Um Olhar Inicial

Para aumentar a confiabilidade da pesquisa, essa foi guiada de acordo com o protocolo de estudo de caso proposto por Yin (2005) que contou com uma visão geral da pesquisa; procedimentos de campo, análise documental, roteiro de entrevistas semiestruturadas e guia de relatório, descrevendo as atividades e preparação para acontecimentos inesperados (YIN 2005, p.92-102).

$\mathrm{Na}$ segunda etapa da pesquisa, foi realizado o estudo de casos múltiplos sobre o CCPL a partir de três fontes de evidências: entrevistas, observações diretas e documentação. As entrevistas de abordagem direta e pessoal foram guiadas a partir de um roteiro de entrevista semiestruturado com perguntas abertas elaboradas a partir da matriz desenvolvida de variáveis e atributos.

Tabela 1 - Relação de variáveis e atributos

\begin{tabular}{|c|c|c|c|}
\hline \multicolumn{2}{|c|}{ RELAÇÃO DE VARIÁ VEIS E ATRIBUTOS } \\
\hline \multicolumn{2}{|c|}{ GESTÃ DE STAKEHOLDERS } & \multicolumn{2}{c|}{ COCRIAÇÃO DE VALOR } \\
\hline 1 & Identificação & 5 & $\begin{array}{c}\text { Canais de comunicação com os stakeholders: acesso } \\
\text { e diálogo }\end{array}$ \\
\hline 2 & Relacionamento com os stakeholders & 6 & $\begin{array}{c}\text { Participação dos stakeholders na estratégia de } \\
\text { serviços oferecidos + recompensas }\end{array}$ \\
\hline 3 & Hierarquização & 7 & Compartilhamento \\
\hline 4 & Monitoramento do relacionamento & 8 & Transparência \\
\hline
\end{tabular}

Fonte: Elaborado pelas autoras.

Nas entrevistas foi solicitada a assinatura da autorização da transcrição e análise dos dados coletados. Uma ficha com o conceito de Freeman (1984) e mapa de stakeholder foi apresentado para somar às perguntas e direcionar grau de importância/relevância atribuídos pelos gestores. A escolha dos entrevistados foi baseada na representatividade do cargo e a abrangência em relação à gestão, ou seja, pessoas de cargos gerenciais capazes de responder questões sobre gestão e sobre o relacionamento com os diversos stakeholders. No espaço TIM UFMG do Conhecimento foram entrevistadas a diretora administrativa Nadia Nogueira e a coordenadora de comunicação, Laura Guimarães. No Memorial Minas Gerais-Vale os entrevistados foram o gerente geral Wagner Tameirão e a produtora executiva do espaço Maristella de Paula. Foi feito o primeiro contato por telefone e em seguida foi enviada a solicitação de agendamento da entrevista. Ademais, foram 
escolhidos dois stakeholders considerados relevantes: uma representante do governo estadual, a gestora adjunta do CCPL Maria Clara Castro e a gestora municipal do turismo - Belotur Stella Kleinrath.

A observação foi realizada por meio de um roteiro de visita técnica (também baseados na matriz variáveis e atributos) nos museus e nos centros de referência ao turista de Belo Horizonte. Os principais documentos analisados como fontes de evidência foram: livro com a primeira proposta de um circuito cultural para Praça da Liberdade (Pereira, 1997), artigos científicos relacionados ao CCPL, principalmente na área de arquitetura, monografias, sendo uma sobre as funções sociais da Praça da Liberdade e outra sobre o CCPL, artigos jornalísticos, conteúdo dos museus e do CCPL nos respectivos endereços eletrônicos, e folders de divulgação.

A análise dos dados se deu a partir de três fontes principais: entrevistas semiestruturadas, observação guiada por roteiro de visita técnica aos museus e análise de documentos disponíveis online sobre o projeto CCPL e sobre cada museu específico, artigos publicitários, folders de divulgação e programação e artigos de jornal e revistas. Foi apresentado aos entrevistados a definição de stakeholders de Freeman (1984) e após levantamento dos stakeholders identificados pelos gestores foi realizada a avaliação de 1 a 4 de cada um, sendo 4 "Extremamente importante" para o seu empreendimento;3 "Muito importante" para o seu empreendimento;2 "Pouco importante" para o seu empreendimento; 1 "Nada importante" para o seu empreendimento.

Os dados coletados foram avaliados de forma individual e posteriormente agrupadas a partir das variáveis da pesquisa considerando as similaridades e diferenças. A respostas foram avaliadas separadamente com as demais fontes de evidências. Eisenhardt (1989) afirma que não há um formato padrão para as análises, mas ressalta a necessidade buscar a coerência com a teoria. Destaca-se assim a importância das múltiplas fontes de evidência para avaliação de um mesmo fenômeno.

\section{ESTUDO DE CASOS MÚLTIPLOS: ESPAÇO TIM UFMG DO CONHECIMENTO E MEMORIAL MINAS GERAIS- VALE}

Foram pesquisados dois museus, o Espaço TIM UFMG do Conhecimento e o Memorial Minas Gerais - Vale, sendo ambos pertencentes ao CCPL, inaugurados em 2010 e com características administrativas semelhantes, possibilitando assim a análise comparativa.

O Espaço do Conhecimento está localizado no antigo prédio da reitoria da Universidade do Estado de Minas Gerais UFMG, entre o prédio da Rainha da Sucata (futuro centro de informações 
turísticas) e o Museu das Minas e Metal (antiga secretaria da Educação), tendo o patrocínio da empresa de telefonia TIM e da Universidade Federal de Minas Gerais - UFMG e. Foi o primeiro equipamento cultural reformado do CCPL a ser aberto ao público, sendo inaugurado no dia 21 de março de 2010. O prédio de cinco andares mostra a criação do Universo, a vida na Terra e o meio ambiente em cenários interativos. A visita começa pelo quinto andar, onde se situa o planetário, observatório astronômico e o Aleph. O quarto, terceiro e segundo andar fazem parte da exposição Demasiado Humano tendo como subtemas: Origens, Vertentes e Águas. É abordado temas ligados ao conhecimento, origem do universo, surgimento da espécie humana e povoamento da terra, cosmogonias, papel da escrita e diversidade linguística e a biodiversidade. O primeiro andar é a bilheteria, entrada, espaço TIM e o café.

O Memorial Minas Gerais- Vale situa-se na antiga Secretaria da Fazenda, ao lado do atual Museu das Minas e do Metal (Secretaria de Educação) e é mantido pela Fundação Vale. O memorial é dividido em três pavimentos. A visita começa pelo primeiro andar e apresenta ao público a vida e obra de artistas famosos do estado como Guimarães Rosa, Carlos Drummond Andrade, Sebastião Salgado e Lygia Clark. O primeiro andar tem também um café temático (ainda não está em funcionamento), Cyber Lounge e a Midiateca. O Segundo andar revela um pouco da história de Minas Gerais, de sua política, povo e arquitetura (incluindo a história do prédio). No terceiro andar as manifestações populares, o modernismo, o cinema e a tecnologia são os "homenageados". O memorial utiliza recursos virtuais e reúne em um mesmo espaço a riqueza cultural do Estado, desde o século XVIII incluindo o presente e uma perspectiva do futuro

As entrevistas foram conduzidas a partir da definição de Freeman e de uma avaliação prévia de grupos de influência: investidores, clientes, mídia, comunidade local, concorrentes, funcionários, fornecedores, governo e grupos de interesse especiais. Buscou-se identificar nas entrevistas outros grupos de influência, sendo levantados principalmente pessoas com deficiências, classe de $\operatorname{arquitetos}^{5}$ (classificados em grupos de interesses especiais).Relacionado a identificação e hierarquização dos stakeholders, os parceiros e patrocinadores foram os primeiros a serem apontados como de extrema importância, uma vez que são os fornecedores dos recursos financeiros e que estão diretamente inseridos em todo processo, havendo assim necessidade de relacionamento constante. "Sem o investimento das instituições, dos mantenedores, esse circuito não funciona" (TAMEIRÃO, 2011). A diretora administrativa do Espaço TIM UFMG do Conhecimento destacou a particularidade e o desafio do museu de ter a necessidade de alinhamento de interesse das

\footnotetext{
${ }^{5}$ O Sindicado de Arquitetos de Minas Gerais SINARQ/MG entrou com ações para barrar reformas previstas no projeto do CCPL alegando danos ao patrimônio e não cumprimento das normas de preservação universalmente aceitas e ao estatuto da cidade. As maiores críticas eram referentes ao projeto para a Secretaria de Educação, atual Museu das Minas e do Metal
}

Revista Ibero-Americana de Estratégia - RIAE, São Paulo, v. 12, n. 2, p. 274-298, abr./jun. 2013. 
empresas TIM, da UFMG e da CODEMIG. Sinalou também as vantagens de poder contar com uma universidade renomada como a UFMG como parceira, especialmente na formação da equipe e no desenvolvimento de pesquisas. Os parceiros e patrocinadores são identificados como importantes não apenas na função de fornecedores de recursos como são diretamente influenciados pelas ações dos espaços, relacionado diretamente a projeção da marca, do conceito da empresa, apresentando assim a necessidade de monitoramento constante e de feedback do processo. Frooman (1999) destaca a necessidade de atenção constante de alguns stakeholders, como é o caso dos parceiros e patrocinadores.

As características do CCPL (idealização do governo e formação de parceria público privada), os recursos federais e estaduais provenientes de parcerias como UFMG e CODEMIG foram citados como exemplos para listar o governo como um stakeholder de extrema importância, que tem poder, urgência e legitimidade, e que requer atenção e relacionamento constante. “[...] governo precisava da iniciativa privada e ainda precisa pra movimentar o circuito. Então o Circuito é um casamento, e tem que funcionar como casamento, tem relacionamento constante" (TAMEIRÃO, 2011). A comunidade local é apontada como de extrema importância para os gestores, entretanto o trabalho com a mesma é centrada no possível público visitante e não de forma generalizada. Ambos os museus têm trabalhado focando o público escolar em contato direto com as escolas e contatos na secretaria de educação, sendo agora o maior público nos dois museus. Os visitantes/turistas e os funcionários são listados pela gestão dos museus como primordiais. “[...] pra isso operacionalizar tem que ter funcionários dedicados a isso e, temos que ter a pessoa que queira visitar, porque se não tiver ninguém pra ver isso aqui não justifica. Então são os primordiais" (NOGUEIRA, 2011). Wagner Tameirão corrobora e diz que "Os visitantes também são de extrema importância. Não adianta nada ter esse investimento alto do governo, das empresas se a ponta final não é atingida" (TAMEIRÃO, 2011).

Freeman, Harisson e Wicks (2007) apontam que o diálogo com a comunidade deve ser priorizado e constante de forma que a mesma legitime as ações e integre-se ao projeto. Os autores afirmam que conflitos podem ser evitados quando se considera a comunidade local como parceiro relevante. Considerando que museus são instituições a serviço da comunidade e de seu desenvolvimento, com importância singular na dimensão cultural, social e científica, torna-se claro a relevância do engajamento da mesma.

Sobre os funcionários, o gestor do memorial diz que são de extrema importância, pois esses são a linha de frente, a "cara" do espaço. Entretanto não foram apontadas ações específicas sistematizadas, sendo realizado apenas o monitoramento.

Revista Ibero-Americana de Estratégia - RIAE, São Paulo, v. 12, n. 2, p. 274-298, abr./jun. 2013. 
Embora expressado em diferentes graus de relevância (enquanto a gestora do Espaço TIM UFMG do Conhecimento apontou a concorrência como média importância e o gestor do Memorial Minas Gerais - Vale sinalou como de extrema importância), percebe-se que a linha de pensamento é a mesma. Os gestores classificam os concorrentes como parceiros e afirmaram que no campo da cultura o trabalho é complementar. Porém, os museus ainda tem atualmente apenas uma ligação/trabalho direto com os outros museus e espaços do CCPL, não apresentando parcerias específicas externas. Identifica-se nas entrevistas que existe um monitoramento tímido da concorrência, considerado stakeholder de legitimidade. Recentemente estabeleceu-se reuniões para que exista uma integração das ações dos espaços do CCPL, mas transparece a desarticulação em relação aos outros espaços da cidade. Freeman (1894) diz que a importância da gestão tanto dos stakeholders que influenciam quanto que são influenciados apresenta-se na possibilidade de ampliação de suas próprias ações a partir da colaboração e cooperação. Os fornecedores foram avaliados de duas formas pelos gestores: enquanto artistas renomados que atraem público para os espaços, sendo assim importantes; e como demais fornecedores que, embora específicos, são classificados de baixa importância por existir ampla oferta no mercado e não exigir necessariamente um monitoramento de um relacionamento com algum específico. É importante observar que, a partir da identificação da importância do stakeholder para organização, são priorizadas ações de relacionamento e no caso dos fornecedores, não há ações específicas.

A mídia é apontada como média importância, embora tenham dito que dependam dessa para atrair mais visitantes, divulgar os espaços e consequentemente para expansão do CCPL. Os grupos de interesse especial, foram classificados como média e baixa importância e não há nenhuma ação de prevenção ou monitoramento estipulada. Vale a pena destacar que a mídia é considerada como importante para expansão não relacionando a mesma e os grupos de interesses especiais a nenhuma ação que pode ser negativa, ou seja, não há efetivamente ações de antecipação e hierarquização de possíveis prioridades e conflitos.

Em relação aos quatro aspectos base da cocriação de valor, foi possível notar abordagens diferentes. Sabe-se que os museus são recentes e que especialmente o memorial Minas Gerais (que trabalhou no começo apenas com visitas guiadas e número restrito de visitantes) está há pouco aberto ao público em geral. Mas considerando a expertise das empresas parceiras que já tem experiência de incentivos na área cultural, os altos investimentos e mais de um ano de funcionamento, foram analisados com os mesmos critérios.

Os primeiros itens analisados foram o acesso e diálogo. Ambos os museus não apontaram plataformas de comunicação específicas desenvolvidas ou outras plataformas de comunicação comuns (website, twitter, facebook) utilizadas entre estes e seus stakeholders com intuito de 
cocriação de valor. A comunicação com grande parte dos stakeholders é feita basicamente por telefone e online (e-mail). O Espaço TIM UFMG do Conhecimento está nas redes sociais (facebook, twitter e orkut) e desde novembro de 2011 começou a engajar o público em ações interativas, promovendo difusão do conhecimento (artigos e reportagens ligadas ao tema do museu), informando a programação e compartilhando a programações de outros espaços. Essas ações indicam uma busca pela experiência do visitante não apenas no museu, como também fora, sendo assim, um relacionamento contínuo.

Por fazerem parte de um circuito cultural, consequentemente os museus já tem uma ligação mínima com outros equipamentos culturais. A participação e compartilhamento tornou-se mais intensa após algumas reuniões (a primeira em outubro de 2011) estipuladas pelas Expomus (empresa contratada pela gestão do CCPL) que determinaram comitês gestores para constante fluxo de informações entre os espaços.O Espaço TIM UFMG do Conhecimento está na Rede de Museus da UFMG e no IBRAM, . O Memorial Minas - Vale não apontou outras parcerias com espaços culturais, mas demonstrou-se favorável a criação de diálogos e espaços de discussão.

Os gestores dos museus afirmaram são espaços abertos às críticas e que os funcionários participam na elaboração/aprimoramento dos serviços. Entretanto, ambos não apontaram ações estratégias de participação e envolvimento desses, apenas reuniões e diálogos. No mesmo sentido, não foram apontados ações estratégicas de inserção de outros stakeholders no processo de criação e elaboração/aprimoramento dos serviços.

As ações de engajamento do público começaram a acontecer nos dois museus no final de 2011. O Espaço TIM UFMG do Conhecimento teve uma ação chamada "2012 em 12” (o público enviou mensagens que foram projetadas na fechada do museu). O Memorial Vale desenvolveu uma sala onde os visitantes podem levar discos e vídeos e compartilhar (temporariamente fechada) e lançou a campanha para que pessoas levassem fotografias históricas das famílias mineiras.

Referente à transparência e controle de qualidade, os museus afirmaram estar desenvolvendo pesquisas para que sejam aplicadas, mas não há atualmente, nenhum dado quantitativo ou qualitativo relacionado à questões do museu e satisfação do público disponível para consulta.

Referente aos últimos itens analisados relacionados à cocriação de valor, a cooperação e mobilização, também não foram apontados ações específicas trabalhadas por ambos os museus, mas quando questionados sobre interações, canais de troca de informação, treinamento de mão de obra comum dentre outros, as respostas foram todas favoráveis.

É interessante destacar que embora considere alguns stakeholders como de extrema importância, as ações de cocriação que já aconteceram e que estão projetadas tem como foco 
principal os visitantes. Para Prahalad e Krishnan (2008), a base para o desenvolvimento de cocriação de valor é o cooperativismo, ou seja, os diversos stakeholders colaboram para conseguir benefícios. Os stakeholders externos, a gestão do CCPL (administrado atualmente pelo governo do estado) e a gestão do turismo municipal, a Belotur, apontaram algumas questões sobre a importância da cooperação e trabalho em rede.

Maria Clara Castro apontou algumas lacunas que existem não apenas dos espaços como de CCPL como todo que acabam por gerar entraves para o desenvolvimento e expansão do circuito. Dois stakeholders classificados pela gestora como média importância foram a comunidade local e os grupos de interesse especial, embora afirme que essa "pode impactar nos prazos previstos" (referindo especialmente aos de arquitetos que se mobilizaram para paralisar as obras que infringiam, em alguns aspectos, as normas de conservação dos espaços que são tombados). Referente a comunidade local, a gestora diz que "colocaria de média a baixa importância. Deveria ser de extrema importância, mas tal como está hoje é de média ou baixa.A gente tem até o momento pouco relacionamento com a nossa comunidade local" (CASTRO, 2011).

Outra lacuna apontada foi o relacionamento com a gestão do turismo local e as informações e divulgação dos espaços. A gestora aponta que "você chega na praça da liberdade você tem dificuldade de saber informação a respeito de funcionamento, o que está funcionando o que não está, o que vai ser inaugurado". Para suprir essa lacuna, será inaugurado em 2012 o centro de apoio ao turista no prédio da Rainha da Sucata, antigo museu de Mineralogia. Para viabilização desse espaço, será realizada a parceria dos governos municipal, estadual e federal. A Belotur ocupará o prédio que é do governo estadual e o Ministério do Turismo entrará com recursos financeiros.

A parceria com o turismo é importante não apenas para os museus e o circuito como um todo, mas de extrema importância para o turismo da cidade. Stella Kleinrath (2011) lembra "Belo Horizonte tem como posicionamento mercadológico o turismo cultural. Então sem dúvida nenhuma os equipamentos culturais são tanto um foco do nosso trabalho como um suporte". Entretanto, percebe-se que ainda não há um relacionamento constante, uma vez que há uma carência de informações nas centrais de informação ao turista da cidade, de informações do CCPL no guia de Belo Horizonte (atualmente apenas informações dos museus em funcionamento) e nos museus de informações turísticas da cidade (ainda que apenas a distribuição do guia de turismo da cidade com o mapa).

Revista Ibero-Americana de Estratégia - RIAE, São Paulo, v. 12, n. 2, p. 274-298, abr./jun. 2013. 


\section{CONSIDERAÇÕES FINAIS}

Cada vez mais teorias vem surgindo no sentido de orientar e posicionas as empresas no mundo contemporâneo. A Teoria dos Stakeholders por ter os relacionamentos como unidade de análise desloca o foco de apenas estratégico para desenvolvimento e posicionamento das empresas em tempos de instabilidade (uma vez que percebe todas as ameaças e oportunidades), como humano também, pois compreende aqueles que estão sendo diretamente influenciados pela empresa. Buscou-se através das entrevistas, visitas guiadas e análise documental compreender a dinâmica de stakeholders na administração dos museus, identificando a gestão das relações em um plano estratégico e nas ações de cocriação de valor.

Ambos os museus sinalaram o governo, a iniciativa privada (investidores e parceiros) e público como stakeholders primários, ou seja, essenciais para existência da empresa. Para Freeman (1984) esses stakeholders primários possuem relacionamento complexo e exigem monitoramento constante. Para análise de stakeholders de autores como Frooman, a gestão estratégica de uma organização deve necessariamente considerar os objetivos, expectativas e compromissos compreendidos no relacionamento. Entretanto, fica clara a distinção de relacionamento com o governo, parceiros e fornecedores para os visitantes, não havendo ações de relacionamento constante. Foram citadas parcerias com escolas, mas ainda são recentes para poder avaliar.

Os funcionários também foram classificados como de extrema importância, sendo são apontados como a "cara do museu" no Memorial Minas Gerias - Vale. Entretanto, nota-se pelas ações que não há engajamento dos mesmos em ações estratégicas de relacionamento ou mesmo em ações de cocriação de valor. Govier (2008) afirma que a organização deve considerar todos seus stakeholders para que possa realmente criar valor em conjunto. Para o autor, se não houver o comprometimento desde o topo da organização com a cocriação de valor, essa simplesmente não irá acontecer. Os funcionários são envolvidos desde o início, ou seja, cocriação desde o processo e não a utilização de um roteiro pré-definido.

As definições nacionais e internacionais de museus indicam em primeiro lugar, estes como locais a serviço da comunidade, de seu desenvolvimento. Os dois museus posicionaram a comunidade local como stakeholder de extrema importância. Entretanto, nota-se incoerência ao apontar as ações de relacionamento com a mesma. Poucas foram as ações apontadas desde a formação às ações atuais que efetivamente envolvam a comunidade local, especialmente considerando os aspectos de cocriação de valor. Maria Clara Castro afirma que é uma lacuna grande do CCPL como um todo e que há um grande potencial a ser trabalhado, uma vez que a praça é 
próxima a universidades, clubes e está em um dos principais pontos da cidade. Freman, Harisson e Wicks (2007) destacam o diálogo com a comunidade como algo a ser priorizado pelas organizações no sentido não apenas de possivelmente evitar conflitos, mas também de inseri-la como parte integrante dos valores que, no caso dos museus, são representações próprias. Isso significa que os museus têm como objetivo representar legitimamente uma população, sua história, seus valores e estar a favor do desenvolvimento da mesma. Estudos na área de lazer apontam alguns espaços culturais como grandes "elefantes brancos" ou seja, espaços que acabam tornando-se sem valor. Uma das observações das pesquisadoras da não apropriação da comunidade local aos espaços pode ser justificada pelo não engajamento da mesma no processo. De acordo com a gestora do CCPL, o projeto não nasceu de uma necessidade da população detectada, mas sim de uma oportunidade identificada pelo governo de apropriação dos prédios desocupados. Outro ponto a ser destacado na pesquisa é os concorrentes que foram apontados como de pequena importância

Notou-se que somente alguns dos aspectos base da cocriação de valor (diálogo, acesso, avaliação do risco e transparência) são utilizados pela gestão dos espaços. A pesquisa não focou na cocriação em si, mas nos aspectos base e buscou identificar os stakeholders envolvidos. Percebe-se que embora não seja com foco específico de desenvolvimento da cocriação de valor, os museus tem ações pontuais de diálogo e acesso. Não foram listadas ações de avaliação de risco e de transparência. Em ambos os museus o acesso para pessoas com deficiência, por exemplo, é limitado e não há informações precisas ou indicações no percurso da visita. Por fim, a transparência seria as informações completas disponíveis, mas em ambos os museus, principalmente online, as informações não são completas. Percebe-se que já há a conscientização dessa lacuna por parte dos gestores. Quando questionada, por exemplo, sobre possibilidades de reclamação nas redes on-line, Laura Guimarães afirma que a melhor opção é sempre o "jogo aberto”, não esconder a reclamação, mas sim buscar a solução.

As principais ações apontadas pela área de comunicação do Espaço TIM UFMG do Conhecimento são focadas nos visitantes, embora não sejam limitativas, como foi a ação "2012 em 12”. Os funcionários, principalmente do educativo, participam de reuniões, mas não foram indicadas ações de incentivo para melhora nos serviços e recompensas por desenvolvimentos dessas. As reuniões com os outros espaços do circuito podem ser classificadas como plataformas de engajamento, mas são recentes e não é possível afirmar se continuarão após o término do último módulo previsto para janeiro de 2012.

Nota-se que os espaços culturais, embora não estabeleçam como estratégia de gestão, compreendem a influência e importância do trabalho estratégico com os stakeholders e desenvolvem alguns aspectos da cocriação de valor. A gestão de stakeholders realizada considera 
basicamente os stakeholders primários os quais exigem monitoramento constante para que a organização atinja seus objetivos. Entretanto, os stakeholders que sofrem influência direta e atualmente tem uma influência legitima com pouco poder e urgência não são contemplados estrategicamente. A inserção dos mesmos na gestão, além de possibilitar uma visão holística com igualdade de condições na análise, para Freeman (1984) gera cooperação, compartilhamento, transparência e consequentemente benefícios de criação de valor em conjunto com foco na experiência e fortalecimento da economia das redes.

\section{REFERÊNCIAS}

Castells, M. A sociedade em rede. São Paulo: Paz e Terra, 1999, 4 ed..

Circuito Cultural Praça da Liberdade. Museus e espaços. Disponível em: <www.circuitoculturalpracadaliberdade.mg.gov.br>. Acesso em: 02 de ago. de 2011.

Clarkson, M. B. E. A stakeholder framework for analyzing and evaluating corporation. Academy of Management Review. v.20, n.1; p. 92-117, 1995.

Dencker, Ada; Da Via, Sarah. Pesquisa empírica em Ciências Humanas. São Paulo: Futura, 2002.

Donaldson, T.; Preston, L. E. The stakeholder theory of the corporation: concepts, evidence and implications. Academy of Management Review. v.20, n.1, p.65-91, 1995.

Eisenhardt, Kathleen M. Building theories from case study research. The Academy of Management Review, Vol. 14, No. 4. (Oct., 1989), pp. 532-550

Freeman, R. E. Strategic Management: a stakeholder approach. Minnesota: Pitman, 1984.

; Mc Vea, J. A stakeholder approach to Strategic Management. Darden Graduate School of Business Administration. Working Paper No. 01-02, 2001.

; Harisson, Jeffrey; Wicks, Andrew. Managing for stakeholders: survival reputation. Yale University Press. New Haven and London, 2007.

Revista Ibero-Americana de Estratégia - RIAE, São Paulo, v. 12, n. 2, p. 274-298, abr./jun. 2013. 
; Harisson, Jeffrey; Wicks, Andrew; Parmar, Bidhan; De Colle, Simone. Stakeholder Theory: the state of the art. Cambridge: Cambridge University Press, 2010.

Friedman, Andrew L.; MILES, Samantha. Stakeholders: theory and practice. Oxford: Oxford University Press, 2006.

Frooman, Jeff. "Stakeholder Influence strategies." Academy of management review, Vol 24, n2 p.191-205,1999.

Govier, Louise. Leaders in Co-criation? Why and how museums could develop their co-creative practice with the public, building on ideas from the performing arts and other non-museum organizations. MLA Museums Clore Leadership Fellow 2008.

International Council of Museum - ICOM. Museum definition. Disponível em:

<http://www.icom-ce.org/codigo.htm>. Acesso em: 28 mar. 2011.

Instituto Brasileiro de Museus - IBRAM. Guia dos Museus Brasileiros. Brasília, 2011. Disponível em: <www.museus.org.br>. Acesso em 01 e 02 de setembro de 2011.

Junqueira, Rosemeire R., Wada, Elizabeth K. Stakeholders: estratégia organizacional e relacionamento. Estudo de casos múltiplos do setor hoteleiro. Revista Ibero-Americana de Estratégia - RIAE, São Paulo, v. 10, n. 3, p. 94-125, set./dez. 2011.

Mensch, Léontine Meijer-van; Mensch, Peter Van. From Disciplinary control to co-creation collecting and the development of museums as praxis in the nineteenth century. Encouraging Collections Mobility, 2010

Ministério da Cultura, MinC. Dados e Fatos. Disponível em: 〈www.cultura.gov.br >. Acesso em: 01 e 02 de set. de 2010.

. Política Nacional de Museus - Bases para a Política Nacional de Museus, 2007. Disponível em: < http://www.cultura.gov.br/site/wp-content/uploads/2007/09/bases-para-a-politicanacional-de-museus.pdf $>$ Acesso em: 01 de ago. de 2010

Mitchell, Ronald K.; Agle, Bradley R.; Wood, Donna J. Toward a theory of stakeholder identification and salience: defining the principle of who and what really counts. Academy of Management Review, v. 22, n. 4, p. 853-886, 1997

Prahalad, C.K.; Romaswamy, Venkant. O futuro da competição: como desenvolver diferenciais inovadores em parceria com os clientes. 4 ed. Rio de Janeiro: Elsevier, 2004.

Reed, M.S.;Graves, A.; Dandy, N.; Posthumus, H.; Hubacek, K.; Morris, J.; Prell, C.; Quinn, C. H.; Stringer, L. C. Who's in and Why? A typology of stakeholder analysis methods for natural resource management. Journal of Environmental Management, 90, 1933-1949 Feb. 2009. Disponível em: <http://dx.doi.org/10.1016/j.jenvman.2009.01.001> . Acesso em: 28 dec. 2011. 
Romaswamy, Venkant; Gouillart, Francis. A empresa co-criativa. Rio de Janeiro: Elsevier; São Paulo: Symnetics, 2010.

Secretaria de Cultura de Minas Gerais- SEC/MG. Fomento e Incentivo a Cultura. Disponível em: <www.cultura.mg.gov.br >. Acesso em: 29 e 30 de agosto de 2011.

Yin, Robert K. Estudo de caso: planejamento e métodos. Porto Alegre: Bookman, 2005.

Recebido: 21/02/2013

Aprovado: 16/04/2013

Revista Ibero-Americana de Estratégia - RIAE, São Paulo, v. 12, n. 2, p. 274-298, abr./jun. 2013. 